\title{
PENGARUH MARKETING MIX-7P DAN RELIGI TERHADAP KEPUTUSAN MENJADI NASABAH (Survey Pada PT. Bank BRISyariah KCP Wahid Hasyim Jombang)
}

\author{
Haqiqotus Sa'adah'1, Imam Sopingi ${ }^{2}$ \\ 1,2 Universitas Hasyim Asy'ari Jombang \\ haqiqotussaadah24@gmail.com
}

\begin{abstract}
: This study aims to test how far the decision to become a customer or customer interest in sharia banking, especially PT. Bank BRISyariah KCP Wahid Hasyim Jombang by observing customer's behaviors. Data collection conducted in this research is interview, literature study, and distribution of questionnaires using Likert scale and sample determination method used is simple random sampling of 100 samples. The analysis method used is multiple linear regression analysis.

The results showed that marketing mix-7p variables (X1) and religion variables (X2), had a positive influence. The regression equation $Y=-5.792+$ $0.234+0.644$. The F test (simultaneous) showed that the marketing mix-7p variables and religion variables both had significant influences on the decision to be a customer with a significance level of 0.000 or $0 \%$. But based on $T$ test (partial), marketing mix-7p variables significantly influence the decision to become a customer of 0,000, while religious variables significantly influence the decision to become a client of 0.001. The contribution of marketing mix-7p and religion variables to the decisions to become customers is shown by the coefficient of determination that has been equaled 0.783 means that the marketing mix-7p and religion influence the decision to become a customer of $78.3 \%$ while sisahnya by $22 \%$ influenced by other variables outside the model Used by researchers.And the result of this research get $R=0,885$ show $R$ almost close to number 1 , meaning between marketing mix-7p and religion variable to decision become customer have influence.
\end{abstract}

Keywords $\quad$ :Marketing mix-7p, religion, decision to be a customer.

\section{LATAR BELAKANG}

Hal mendasar yang membedakan antara lembaga keuangan konvensional dan syariah adalah terletak pada pengambilan dan pembagian keuntungan yang diberikan oleh lembaga keuangan kepada nasabah. Sehingga terdapat istilah bunga dan bagi hasil (Sudarsono, 2004). Berdasarkan UU No. 21 tahun 2008 tentang perbankan syariah disebutkan dalam pasal 1 bahwa perbankan syariah adalah segala sesuatu yang menyangkut tentang Bank Syariah dan Unit Usaha Syariah.

Menurut Muhammad (2005:13), bank Islam atau selanjutnya disebut dengan bank syariah adalah bank yang beroperasi tanpa menggunakan bunga. Bank Islam atau biasa disebut bank beroperasi tanpa bunga, adalah lembaga/perbankan yang operasional dan produknya dikembangkan berlandasan pada Al-Qur'an dan Hadits Nabi SAW. 
Berdasarkan Fatwa MUI tahun 2014 tentang bunga bank. Pembungaan tersebut hukumnya adalah haram, baik dilakukan oleh Bank, Asuransi, Pasar Modal, Penggadaian, Koperasi, dan Lembaga Keuangan lainnya maupun dilakukan oleh individu. Hal ini sesuai dengan yang diungkapkan dalam Q.S Al-Baqarah (02:275276).

Bank syariah dengan sistem bagi hasilnya sebagai alternatif pengganti dari penerapan sistem bunga ternyata dinilai telah berhasil menghindarkan dampak negatif dari penerapan bunga, seperti (a) pembebanan pada nasabah berlebihlebihan dengan beban bunga berbunga (compound interest) bagi nasabah yang tidak mampu membayar pada saat jatuh tempo, (b) timbulnya pemerasan (eksploitasi) yang kuat terhadap yang lemah, (c) terjadinya konsentrasi kekuatan ekonomi di tangan kelompok elit, para Bankir dan pemilik modal, (d) kurangnya peluang bagi kekuatan ekonomi lemah/bawah untuk mengembangkan potensi usahanya (Sumitro, 2004).

Setiap tindakan yang dilakukan oleh perusahaan atau badan usaha tentu mengandung suatu maksud dan tujuan tertentu. Secara umum tujuan pemasaran bank adalah untuk memaksimumkan konsumsi dengan menarik nasabah untuk membeli produk yang ditawarkan bank secara berulang-ulang, memaksimumkan kepuasan nasabah, menyediakan berbagai jenis produk bank sehingga nasabah memiliki beragam pilihan pula, memberikan berbagai kemudahan kepada nasabah dan menciptakan iklim yang efisien (Kasmir, 2004: 171). Berbagai cara dapat ditempuh untuk mencapai tujuan tersebut, salah satunya adalah dengan memahami kebutuhan dan keinginan pasar untuk dijadikan dasar merumuskan strategi dalam merangsang proses pengambilan keputusan nasabah.

Nasabah memiliki sikap yang berbeda-beda dalam menilai perusahaan perbankan, pada kondisi pasar pembeli, nasabah haruslah dapat membeli aneka macam tawaran produk/jasa bank. Bank harus dapat memberikan pelayanan yang prima dan apabila tidak maka nasabah akan segera berpaling ke bank lain yang dapat memberikan kualitas layanan yang lebih baik. Agar bank dapat menang dalam persaingan dan tetap bertahan hidup maka bank harus berwawasan pelanggan. Di antaranya adalah pelayanan yang baik, nisbah bagi hasil yang adil, proses yang cepat dan tepat dan kualitas produk harus ditingkatkan (Abdullah, 2003).

Keputusan menjadi nasabah perbankan merupakan elemen penting dalam menumbuh kembangkan perbankan agar tetap eksis dalam menghadapi persaingan. Demikian pula dengan perbankan syariah, merupakan perusahaan yang berdasarkan pada asas kepercayaan, sehingga lembaga keuangan syariah harus bisa menciptakan produk yang benar-benar berkualitas dan mampu bersaing dengan lembaga-lembaga keuangan lainnya.

Perkembangan PT. Bank BRISyariah KCP Wahid Hasyim Jombang hingga saat ini yang menggunakan prinsip syariah mengalami peningkatan. Hal tersebut dilatarbelakangi oleh keinginan umat Islam untuk menghindari bunga dalam kegiatan muamalahnya dan memperoleh kesejahteraan lahir batin melalui kegiatan muamalah yang sesuai dengan perintah agamanya. Negara Indonesia yang mayoritas penduduknya beragama muslim terbesar di dunia juga telah merasakan kebutuhan akan adanya Bank Syariah yang diharapkan dapat memberikan kemudahankemudahan kepada semua umat muslim dan penduduk di Indonesia yang beroperasi tanpa bunga.

Melalui latar belakang masyarakat indonesia yang berdominan beragaman Islam dan keinginan umat Islam menghindari bunga tersebut. Apakah religi menjadi 
faktor utama nasabah dalam memutuskan menjadi nasabah di PT. Bank BRISyariah KCP Wahid hasyim Jombang. Sedangkan nasabah di PT. Bank BRISyariah KCP Wahid hasyim Jombang meningkat 20\% dalam setiap tahunnya.

Religi merupakan bentuk aspek religiusitas yang telah dihayati oleh individu di dalam hati. Makna religiusitas digambarkan dalam beberapa aspek-aspek yang harus dipenuhi sebagai petunjuk mengenai bagaimana cara menjalankan hidup dengan benar agar manusia dapat mencapai kebahagiaan, baik di dunia dan ahirat (Lestari, 2015).

Masalah ketertarikan atau keputusan menjadi nasabah, tanggapan nasabah terhadap perbankan syariah merupakan salah satu bagian dari aspek pemasaran. Philip Kotler \& Keller (2009), menyatakan bahwa bauran pemasaran (marketing mix) adalah seperangkat alat pemasaran yang digunakan perusahaan untuk terus menerus mencapai tujuan perusahaannya di pasar sasaran yang meliputi produk (product), harga (price), tempat (place), promosi (promotion), orang (people) proses (process), lingkungan fisik (physical evidence). Setiap perusahaan selalu berharap produknya dapat diterima oleh pasar. Salah satu ciri bahwa produknya dapat diterima adalah dilakukannya pembelian oleh nasabah terhadap produk tersebut.

Penggunaan marketing mix (bauran pemasaran) dalam dunia perbankan dilakukan dengan menggunakan konsep-konsep yang sesuai dengan kebutuhan bank. Dalam praktiknya, konsep bauran pemasaran tersendiri dari bauran pemasaran untuk produk yang berupa barang maupun jasa. Khusus untuk produk yang berbentuk barang jasa diperlakukan konsep sedikit berbeda dengan produk barang.

Untuk mencapai tujuan pemasaran, maka ketujuh unsur tersebut harus saling mendukung satu dengan yang lain, dengan kata lain manajemen harus berusaha agar variabel-variabel marketing mix dapat terpadu untuk mencapai tujuan yang telah ditetapkan perusahaan. Jadi tidak hanya salah satu komponen saja yang diprioritaskan, tetapi apabila perusahaan ingin memenuhi kebutuhan secara memuaskan maka harus didukung oleh ketujuh unsur tersebut di atas (Murti dan John, 2010).

Rumusan masalah pada penelitian ini adalah bagaimana variabel marketing mix$7 P$ yang terdiri dari produk, harga, lokasi, promosi, orang, proses, lingkungan fisik secara parsial berpengaruh signifikan terhadap keputusan menjadi nasabah di PT. Bank BRISyariah KCP Wahid Hasyim Jombang? Bagaimana variabel religi secara parsial berpengaruh signifikan terhadap keputusan menjadi nasabah di PT. Bank BRISyariah KCP Wahid Hasyim Jombang? Bagaimana variabel marketing mix-7P yang terdiri dari produk, harga, lokasi, promosi, orang, proses, lingkungan fisik dan variabel religi secara simultan berpengaruh signifikan terhadap keputusan menjadi nasabah di PT. Bank BRISyariah KCP Wahid Hasyim Jombang?

Penelitian ini bertujuan untuk mengetahui dan menjelaskan variabel marketing mix-7P yang terdiri dari produk, harga, lokasi, promosi, orang, proses, lingkungan fisik secara parsial berpengaruh signifikan terhadap keputusan menjadi nasabah di PT. Bank BRISyariah KCP Wahid Hasyim Jombang. Variabel religi secara parsial berpengaruh signifikan terhadap keputusan menjadi nasabah di PT. Bank BRISyariah KCP Wahid Hasyim Jombang. Variabel marketing mix-7P yang terdiri dari produk, harga, lokasi, promosi, orang, proses, lingkungan fisik dan variabel religi secara simultan berpengaruh signifikan terhadap keputusan menjadi nasabah di PT. Bank BRISyariah KCP Wahid Hasyim Jombang. 


\section{TEORI DAN METODE}

Kerangka konseptual yang baik akan menjelaskan secara teoritis pertautan antar variabel yang akan diteliti. Jadi secara teoritis perlu dijelaskan hubungan antara variabel independen dan dependen. Kerangka konseptual dalam suatu penelitian perlu dikemukakan apabila dalam penelitian tersebut berkenan dua variabel atau lebih (Sugiyono, 2015). Maka kerangka konseptual dalam penelitian ini menjadi penting sehingga akan diketahui seperti apa dan bagaimana alur dari penelitian ini. Kerangka konseptual yang akan disaji dapat susun suatu kerangka konseptual untuk menganalisis pengaruh marketing mix-7P dan religi terhadap keputusan menjadi nasabah (survey pada PT. Bank BRISyariah KCP Wahid Hasyim Jombang). Adapun indikator dari marketing mix yang terdiri dari 7P, yaitu: produk (product), harga (price), promosi (promotion), lokasi (place), partisipan (people), proses (process), lingkungan fisik (phisical evidence).

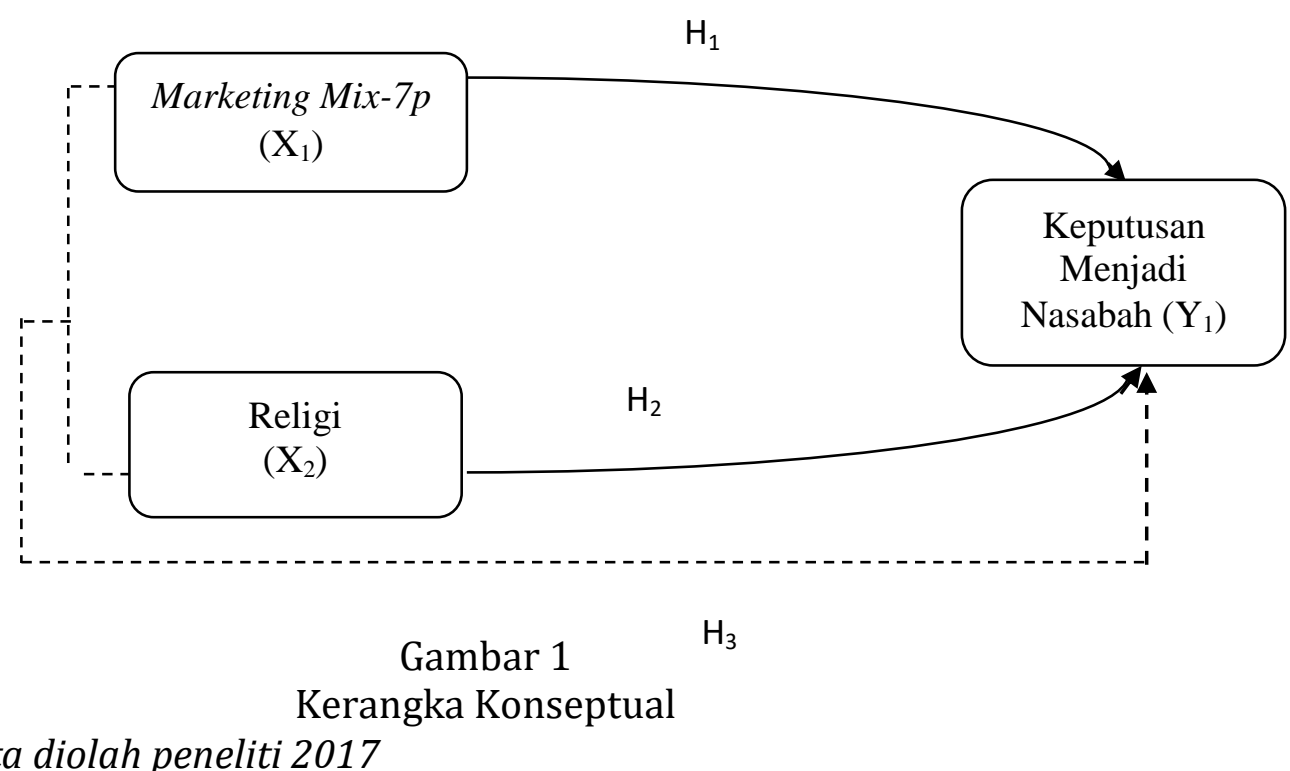

\section{Sumber: Data diolah peneliti 2017}

Jenis penelitian yang dilakukan adalah metode penelitian survey, yaitu suatu penelitian yang mengambil sampel dari suatu populasi dan menggunakan kuesioner sebagai alat pengumpulan data dan bertujuan untuk menggambarkan, menjelaskan, memaparkan suatu fenomena tertentu melalui kegiatan penelitian lapangan (Sugiyono, 2015: 12).

Penelitian ini dilakukan di PT. Bank Brisyariah KCP Wahid Hasyim Jombang yang terletak di Jalan Wahid Hasyim Nomor 9 Blok A1-A2 Jombang, dengan meneliti keputusan menjadi nasabah sebagai pengguna jasa BRISyariah, pemilihan tempat penelitian ini didasarkan atas pertimbangan bahwa PT. Bank BRISyariah KCP Wahid Hasyim Jombang letak berdirinya yang berada di wilayah perkotaan maka sangat mudah dalam penjangkauannya.

Populasi pada penelitian ini adalah seluruh nasabah pada tahun 2016 PT. Bank BRISyariah KCP Wahid Hasyim Jombang yang berjumlah 15420 nasabah. Adapun sample pada penelitian ini adalah 100 responden dengan batas toleransi kesalahan $10 \%$ dengan teknik penentuan jumlah sample menggunakan rumus Slovin (Amirin, 2011).

Definisi operasional variabel sebagai berikut yang dipakai dalam penelitian ini adalah sebagai berikut: 
Marketing mix-7P $\left(\mathrm{X}_{1}\right)$ adalah seperangkat alat pemasaran yang digunakan perusahaan/perbankan untuk mencapai tujuan pemasarannya dalam pasar sasaran. Adapun pengukuran marketing mix-7p yang terdiri dari produk, harga, tempat, promosi, orang, proses, lingkungan fisik:

1. Produk setiap apa saja yang dapat ditawarkan di pasar untuk mendapatkan perhatian, permintaan, pemakaian atau konsumsi yang dapat memenuhi keinginan atau kebutuhan nasabah. Produk yang ada di PT. Bank BRISyariah KCP Wahid Hasyim Jombang terdiri dari tabungan, pembiayaan, dan jasa.

2. Harga, biaya pembukaan dan penutupan rekening yang harus di tanggung oleh nasabah dan manfaat atau porsi (nisbah) bagi hasil yang didapatkan oleh nasabah serta beban yang harus dibayar oleh nasabah dan sistem bagi hasil yang kompetitif.

3. Tempat, menentukan lokasi bagaimana produk tersebut mudah didapatkan dan tempat yang strategis dan nyaman, aman dalam menunjang keberhasilan penjualan.

4. Promosi, cara-cara nasabah dalam menerima informasi mengenai produk yang ditawarkan PT. Bank BRISyariah KCP Wahid Hasyim Jombang sebagai kegiatan pemasaran dengan cara periklanan, promosi penjualan, publisitas, dan penjualan pribadi.

5. Orang, pegawai yang dimiliki oleh PT. Bank BRISyariah KCP Wahid Hasyim Jombang yaitu customer service, teller, dan marketing yang berperan dalam pengelolaan usaha peruahaan.

6. Proses, suatu prosedur, mekanisme, dan rangkaian kegiatan untuk menyampaikan produk dari produsen ke nasabah ketika melakukan transaksi.

7. Lingkungan fisik, suatu hal yang secara nyata turut mempengaruhi persepsi nasabah untuk membeli dan menggunakan produk yang ditawarkan.

Religi $\left(\mathrm{X}_{2}\right)$ religi adalah faktor yang bersifat dogmatis dimana kebenarannya diyakini secara mutlak oleh setiap individu. Pengukuran berdasarkan sistem syari'ah yang dioperasionalkan oleh PT. Bank BRISyariah KCP Wahid Hasyim Jombang.

Keputusan menjadi nasabah $\left(\mathrm{Y}_{1}\right)$ keputusan pembelian/menabung untuk menjadi nasabah adalah sebuah keputusan yang diambil oleh nasabah untuk membeli sebuah produk dengan mempertimbangkan berbagai alasan terlebih dahulu.

Data yang diinginkan dalam penelitian ini adalah data-data mengenai faktorfaktor yang mempengaruhi keputusan menjadi nasabah. Data ini meliputi: Data primer, yaitu data yang bersumber dari kuesioner penelitian yang dijawab nasabah PT. Bank BRISyariah KCP Wahid Hasyim Jombang. Data sekunder, yaitu data bersumber dari buku-buku, serta tulisan yang berhubungan dengan masalah yang sedang diteliti.

Dalam pengumpulan data yang akan digunakan dalam penelitian ini dilakukan dengan beberapa teknik pengumpulan data, yaitu: Penyebaran angket (Questioner), wawancara, srudi kepustakaan.

Analisis data dilakukan dengan menggunakan statistik deskriptif. Statistik deskriptif adalah stastiktik yang digunakan untuk menganalisis data dengan cara mendeskripsikan atau menggambarkan data yang telah terkumpul sebagaimana adanya tanpa bermaksud membuat kesimpulan yang berlaku untuk umum atau generalisasi. Metode kuantitatif ini yang akan penulis gunakan untuk mengetahui seberapa besar pengaruh variabel marketing mix-7P (produk, harga, tempat, promosi, orang, proses, lingkungan fisik) dan variabel religi terhadap keputusan menjadi nasabah pada PT. Bank BRISyariah KCP Wahid Hasyim Jombang. Proses analisis data 
di awali dengan Uji Instrumen, Uji Hipotesis, Uji Asumsi Klasik. Analisis data dijalankan dengan program SPSS (Statistical Product and Service Sollution) for Windows versi 23.0.

\section{PEMBAHASAN}

Uji regresi linear berganda adalah model analisis dengan menguji pengaruh variabel independen lebih dari satu terhadap variabel dependen.

Tabel 1. Uji Validitas Instrumen Penelitian

\begin{tabular}{|c|l|l|l|l|l|}
\hline Variabel & \multicolumn{1}{|c|}{$\begin{array}{c}\text { Kode } \\
\text { Indikator }\end{array}$} & \multicolumn{1}{|c|}{$\mathrm{r}_{\text {hitung }}$} & \multicolumn{1}{c|}{$\mathrm{r}_{\text {tabel }}$} & Probability & Ket. \\
\hline Marketing Mix & $\mathrm{X} 1.1$ & 0,902 & 0,30 & 0,000 & Valid \\
& $\mathrm{X} 1.2$ & 0,778 & 0,30 & 0,000 & Valid \\
\cline { 2 - 6 } & $\mathrm{X} 2.1$ & 0,883 & 0,30 & 0,000 & Valid \\
& $\mathrm{X} 2.2$ & 0,867 & 0,30 & 0,000 & Valid \\
\cline { 2 - 6 } & $\mathrm{X} 3.1$ & 0,902 & 0,30 & 0,000 & Valid \\
& $\mathrm{X} 3.2$ & 0,778 & 0,30 & 0,000 & Valid \\
\cline { 2 - 6 } & $\mathrm{X} 4.1$ & 0,764 & 0,30 & 0,000 & Valid \\
& $\mathrm{X} 4.2$ & 0,760 & 0,30 & 0,000 & Valid \\
\cline { 2 - 6 } & $\mathrm{X} 5.1$ & 0,933 & 0,30 & 0,000 & Valid \\
& $\mathrm{X} 5.2$ & 0,861 & 0,30 & 0,000 & Valid \\
\cline { 2 - 6 } & $\mathrm{X} 6.1$ & 0,905 & 0,30 & 0,000 & Valid \\
& $\mathrm{X} 6.2$ & 0,797 & 0,30 & 0,000 & Valid \\
\cline { 2 - 6 } & $\mathrm{X} 7.1$ & 0,897 & 0,30 & 0,000 & Valid \\
& $\mathrm{X} 7.2$ & 0,861 & 0,30 & 0,000 & Valid \\
\hline Religi & $\mathrm{X} 2.1$ & 0,738 & 0,30 & 0,000 & Valid \\
& $\mathrm{X} 2.2$ & 0,460 & 0,30 & 0,011 & Valid \\
& $\mathrm{X} 2.3$ & 0,821 & 0,30 & 0,000 & Valid \\
\hline Keputusan & $\mathrm{Y} 1.1$ & 0,830 & 0,30 & 0,000 & Valid \\
Menjadi & $\mathrm{Y} 1.2$ & 0,711 & 0,30 & 0,000 & Valid \\
Nasabah & $\mathrm{Y} 1.3$ & 0,626 & 0,30 & 0,000 & Valid \\
& $\mathrm{Y} 1.4$ & 0,768 & 0,30 & 0,000 & Valid \\
\hline
\end{tabular}

Sumber: Data primer yang diolah SPSS 23.0

Berdasarkan hasil uji validitas atas variabel marketing mix-7p yang terdiri dari: produk, harga, tempat, promosi, orang, proses, lingkungan fisik, nampak bahwa dari 7 indikator yang diteliti dengan jumlah pernyataan 14 maka dapat disimpulkan bahwa semua item pernyataan dinyatakan valid karena memiliki nilai corrected item total correlation di atas 0,30, sedangkan untuk variabel religi dengan item 3 pernyataan, maka dinyatakan semua item valid karenan memiliki nilai corrected item total correlation di atas dari 0,30. Sedangkan untuk variabel keputusan menjadi nasabah dengan 4 item pernyataan, maka semua item dinyatakan valid karena memiliki nilai corrected item total correlation di atas 0,30.

Tabel 2. Uji Reliabilitas Instrumen Penelitian

\begin{tabular}{|l|l|l|l|}
\hline Variabel & Nilai Cronbach's Alpha & Standar & Keterangan \\
\hline Marketing Mix & 0,914 & 0,60 & Reliabel \\
\hline Religi & 0,801 & 0,60 & Reliabel \\
\hline $\begin{array}{l}\text { Keputusan Menjadi } \\
\text { Nasabah }\end{array}$ & 0,874 & 0,60 & Reliabel \\
\hline
\end{tabular}

Sumber: Data primer yang diolah SPSS 23.0

Hasil uji reliabilitas tersebut menunjukkan bahwa semua variabel mempunyai koefisien yang sangat besar yaitu di atas 0,6 sehingga dapat dikatakan semua alat pengukur masing-masing variabel dari kuesioner adalah reliabel. Sehingga untuk selanjutnya item-item pada masing-masing variabel tersebut layak digunakan sebagai alat ukur. 
Tabel 3. Uji Regresi Linear Berganda

\begin{tabular}{|l|r|r|r|r|r|r|r|}
\hline & \multicolumn{1}{|c|}{$\begin{array}{c}\text { Unstandardized } \\
\text { Coefficients }\end{array}$} & $\begin{array}{c}\text { Standardized } \\
\text { Coefficients }\end{array}$ & & & \multicolumn{2}{|c|}{ Collinearity Statistics } \\
\cline { 2 - 4 } Model & \multicolumn{1}{|c|}{ B } & Std. Error & Beta & \multicolumn{1}{c|}{$\mathrm{T}$} & Sig. & Tolerance & VIF \\
\hline 1 (Constant) & $-5,792$ & 1,710 & & $-3,388$ &, 001 & & \\
MARKETING MIX &, 243 &, 017 &, 775 & 14,340 &, 000 &, 767 & 1,304 \\
RELIGI &, 644 &, 180 &, 194 & 3,583 &, 001 &, 767 & 1,304 \\
\hline
\end{tabular}

a. Dependent Variable: KEPUTUSAN MENJADI NASABAH

Sumber: Data primer yang diolah SPSS 23.0

$$
\begin{aligned}
& Y=a+b_{1} X_{1}+b_{2} X_{2}+e \\
& Y=-5,792+0,234 X_{1}+0,644 X_{2}
\end{aligned}
$$

Dari persamaan regresi liniear berganda di atas, dapat dijelaskan sebagai berikut:

1. Konstanta dari tabel di atas adalah -5,792, menyatakan jika tidak ada marketing mix-7p, religi maka tingkat keputusan menjadi nasabah sebesar 5,417 .

2. Hasil dari marketing mix-7p adalah 0,234 menyatakan bahwa setiap penambahan (karena tanda positif) 1\%, marketing mix-7p akan meningkatkan keputusan menjadi nasabah sebesar Rp. 0,234. Dan sebaliknya, jika marketing mix-7p turun sebesar 1\%, maka keputusan menjadi nasabah juga dipredeksi mengalami penurunan sebesar 0,234 dengan anggapan $\mathrm{X}_{2}$ tetap.

3. Hasil dari religi adalah 0,644 menyatakan bahwa setiap penambahan (karena tanda positif) $1 \%$, religi akan meningkatkan keputusan menjadi nasabah sebesar Rp. 0,644. Dan sebaliknya, jika religi turun sebesar 1\%, maka keputusan menjadi nasabah juga dipredeksi mengalami penurunan sebesar 0,644 dengan anggapan $\mathrm{X}_{1}$ tetap.

\section{Tabel 4. Uji Normalitas}

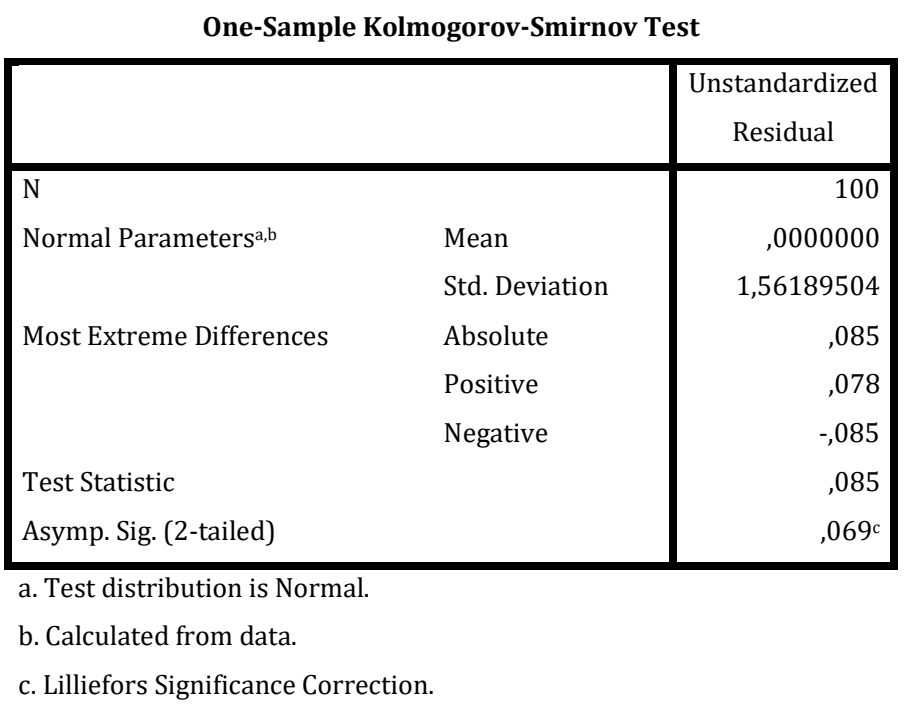

Sumber: Data primer yang diolah SPSS 23.0 
Tabel di atas menunjukkan bahwa nilai Asymp. Sig. (2-tailed) sebesar 0,069 ini berarti residual berdistribusi normal, karena nilai signifikan yang dihasilkan lebih besar dari 0,05 maka terima Ho maka dapat disimpulkan bahwa residual berdistribusi normal.

Tabel 5. Uji Multolinearitas

Coefficients $^{\mathrm{a}}$

\begin{tabular}{|c|c|c|c|c|c|c|c|}
\hline \multirow[b]{2}{*}{ Model } & \multicolumn{2}{|c|}{$\begin{array}{c}\text { Unstandardized } \\
\text { Coefficients }\end{array}$} & \multirow{2}{*}{$\begin{array}{c}\begin{array}{c}\text { Standardized } \\
\text { Coefficients }\end{array} \\
\text { Beta }\end{array}$} & \multirow[b]{2}{*}{$\mathrm{T}$} & \multirow[b]{2}{*}{ Sig. } & \multicolumn{2}{|c|}{ Collinearity Statist ics } \\
\hline & B & Std. Error & & & & Tolerance & VIF \\
\hline 1 (Constant) & $-5,792$ & 1,710 & & $-3,388$ & ,001 & & \\
\hline MARKETING MIX & ,243 & ,017 & ,775 & 14,340 & ,000 & ,767 & 1,304 \\
\hline RELIGI & ,644 & 180 & 194 & 3,583 & ,001 & ,767 & 1,304 \\
\hline
\end{tabular}

a. Dependent Variable: KEPUTUSAN MENJADI NASABAH

Sumber: Data primer yang diolah SPSS 23.0

Dari data tersebut dapat disimpulkan bahwa tidak terjadi multikolinearitas. Hal ini karena hasil yang ditujukkan oleh VIF kurang dari 10 yaitu pada marketing mix-7p dan religi menunjukkan nilai 1,304. Pada hasil yang ditunjukkan oleh Tolerance yaitu lebih dari 0,10 adalah sebesar 0,767.

Tabel 6. Uji Heteroskedasitas

\begin{tabular}{|l|r|r|r|r|r|}
\hline \multirow{2}{*}{ Model } & \multicolumn{2}{|c|}{$\begin{array}{c}\text { Unstandardized } \\
\text { Coefficients }\end{array}$} & $\begin{array}{c}\text { Standardized } \\
\text { Coefficients }\end{array}$ & & \\
\cline { 1 - 4 } & \multicolumn{1}{|c|}{ B } & Std. Error & Beta & \multirow{2}{*}{ T } & Sig. \\
\hline (Constant) & $-1,847 \mathrm{E}-15$ & 1,710 & &, 000 & 1,000 \\
MARKETING MIX &, 000 &, 017 &, 000 &, 000 & 1,000 \\
RELIGI &, 000 &, 180 &, 000 &, 000 & 1,000 \\
\hline
\end{tabular}

Sumber: Data primer yang diolah SPSS 23.0

Tabel 7. Uji Koefisien Determinasi $\left(\mathrm{R}^{2}\right)$

\begin{tabular}{|l|r|r|r|r|r|}
\hline Model & $\mathrm{R}$ & $\mathrm{R}$ Square & $\begin{array}{c}\text { Adjusted R } \\
\text { Square }\end{array}$ & $\begin{array}{c}\text { Std. Error of the } \\
\text { Estimate }\end{array}$ & Durbin-Watson \\
\hline 1 &, $885^{\mathrm{a}}$ &, 783 &, 778 & 1,578 & 1,172 \\
\hline
\end{tabular}
a. Predictors: (Constant), RELIGI , MARKETING MIX
b. Dependent Variable: KEPUTUSAN MENJADI NASABAH

Sumber: Data primer yang diolah SPSS 23.0

Berdasarkan tabel di atas, menunjukan bahwa nilai koefisien determinasi ( $\mathrm{R}$ Square) adalah 0,783 dan koefisien determinasi yang disesuaikan (Adjusted $\mathrm{R}$ Square) adalah 0,778 artinya, marketing mix-7p dan religi berpengaruh terhadap keputusan menjadi nasabah sebesar $78,3 \%$ dan sisanya $22,7 \%$ dipengaruhi oleh variabel lain diluar model yang digunakan oleh peneliti. 
$\mathrm{R}$ dalam model summary ini sebesar 0,885 menunjukan bahwa $\mathrm{R}$ sangat mendekati angka 1 artinya adalah variabel marketing mix-7p dan religi mempunyai pengaruh terhadap keputusan menjadi nasabah.

Tabel 8. Uji F (simultan)

\begin{tabular}{|c|c|c|c|c|c|}
\hline \multicolumn{6}{|c|}{ ANOVA $^{a}$} \\
\hline Model & $\begin{array}{l}\text { Sum of } \\
\text { Squares }\end{array}$ & Df & $\begin{array}{l}\text { Mean } \\
\text { Square }\end{array}$ & $\mathrm{F}$ & Sig. \\
\hline Regression & 870,728 & 2 & 435,364 & 174,858 &, $000^{\mathrm{b}}$ \\
\hline Residual & 241,512 & 97 & 2,490 & & \\
\hline Total & 1112,240 & 99 & & & \\
\hline
\end{tabular}

Berdasarkan data tabel di atas menunjukkan bahwa nilai signifikansinya sebesar 0,000 dimana nilai ini lebih kecil dari 0,05 dan $\mathrm{f}$ hitung $(174,858)<\mathrm{f}$ tabel $(3,09)$ maka hipotesis terima $\mathrm{H}_{1}$, artinya marketing mix-7p dan religi secara simultan terdapat pengaruh terhadap keputusan menjadi nasabah

\section{Tabel 9. Uji T-test (parsial)}

\begin{tabular}{|c|c|c|c|c|c|}
\hline \multirow[b]{3}{*}{ Model } & \multicolumn{3}{|c|}{ Coefficients ${ }^{\mathrm{a}}$} & \multirow[b]{3}{*}{$\mathrm{T}$} & \multirow[b]{3}{*}{ Sig. } \\
\hline & \multicolumn{2}{|c|}{$\begin{array}{c}\text { Unstandardized } \\
\text { Coefficients }\end{array}$} & \multirow{2}{*}{$\begin{array}{c}\begin{array}{c}\text { Standardized } \\
\text { Coefficients }\end{array} \\
\text { Beta }\end{array}$} & & \\
\hline & B & Std. Error & & & \\
\hline (Constant) & $-5,792$ & 1,710 & & $-3,388$ & ,001 \\
\hline MARKETING MIX & ,243 & ,017 & ,775 & 14,340 & ,000 \\
\hline RELIGI & 644 & 180 & 194 & 3,583 & ,001 \\
\hline
\end{tabular}

Sumber: Data primer yang diolah SPSS 23.0

Berdasarkan hasil uji t-test dapat dijelaskan pengaruh antara variabel independen terhadap variabel dependen sebagai berikut:

Nilai signifikansi marketing mix-7p lebih kecil dari 0,05 yaitu 0,001 . Dan nilai t hitung $(14,340)<t$ tabel $(1.98472)$. Dengan demikian hipotesis $\mathrm{H}_{1}$ diterima, hal ini menujukkan bahwa marketing mix-7p mempunyai pengaruh terhadap keputusan menjadi nasabah. Namun pada kolom t menunjukkan nilai sebesar 14,340 ini berarti bahwa arah hubungan antara marketing mix-7p dengan keputusan menjadi nasabah searah.

Nilai signifikansi religi lebih kecil dari 0,05 yaitu 0,000 . Dan nilai t hitung $(3,583)<\mathrm{t}$ tabel (1.98472). Dengan demikian hipotesis $\mathrm{H}_{1}$ diterima, hal ini menujukkan bahwa religi mempunyai pengaruh terhadap keputusan menjadi nasabah. Namun pada kolom t menunjukkan nilai sebesar 3,583 ini berarti bahwa arah hubungan antara religi dengan keputusan menjadi nasabah searah.

Tabel 10. Uji T-test (parsial) Marketing mix-7p 
Coefficients $^{\mathrm{a}}$

\begin{tabular}{|c|c|c|c|c|c|}
\hline \multirow[b]{2}{*}{ Model } & \multicolumn{2}{|c|}{$\begin{array}{c}\text { Unstandardized } \\
\text { Coefficients }\end{array}$} & \multirow{2}{*}{$\begin{array}{c}\begin{array}{c}\text { Standardized } \\
\text { Coefficients }\end{array} \\
\text { Beta }\end{array}$} & \multirow[b]{2}{*}{$\mathrm{T}$} & \multirow[b]{2}{*}{ Sig. } \\
\hline & B & Std. Error & & & \\
\hline 1 (Constant) & ,885 & 1,091 & & ,811 & ,020 \\
\hline Produk & ,250 & 109 & ,251 & 2,293 & ,014 \\
\hline Harga & ,035 & 107 & 037 & ,327 & 024 \\
\hline Tempat & ,267 & 109 & ,250 & 2,438 & ,017 \\
\hline Promosi & 141 & 121 & 123 & 1,170 & ,035 \\
\hline Orang & ,103 & 134 & ,098 & ,763 & ,012 \\
\hline Proses & ,124 & ,113 & ,134 & 1,097 & ,025 \\
\hline $\begin{array}{l}\text { Lingkungan } \\
\text { Fisik }\end{array}$ & ,236 & 129 & 182 & 1,823 & ,032 \\
\hline
\end{tabular}

a. Dependent Variable: Keputusan Menjadi Nasabah

Sumber: Data primer yang diolah SPSS 23.0

\section{Pengaruh Marketing mix-7p Secara Parsial Terhadap Keputusan Menjadi Nasabah PT. Bank BRISyariah KCP Wahid Hasyim Jombang}

Dari hasil uji yang telah dilakukan, menunjukkan bahwa variabel marketing mix$7 p$ (produk, harga, tempat, promosi, orang, proses, lingkungan fisik) berpengaruh positif terhadap keputusan menjadi nasabah PT. Bank BRISyariah KCP Wahid Hasyim Jombang. Dari hasil peritungan koefisien regresi marketing mix-7p diperoleh nilai sebesar 0,243 dan nilai constant sebesar -5,792. Angka tersebut menunjukkan bahwa marketing mix-7p berpengaruh terhadap keputusan menjadi nasabah PT. Bank BRISyariah KCP Wahid Hasyim Jombang. Artinya marketing mix-7p meningkatkan keputusan menjadi nasabah sebesar $0,234 \%$ dengan kata lain jika marketing mix-7p meningkat sebesar 1\% maka keputusan menjadi nasabah juga akan meningkat sebesar $0,234 \%$.

Signifikansi pada uji t menunjukkan variabel marketing mix-7p berpengaruh terhadap keputusan menjadi nasabah PT. Bank BRISyariah KCP Wahid Hasyim Jombang, di lihat dari nilai signifikansi marketing mix-7p sebesar 0,000 artinya, nilai sig lebih kecil dari 0,05 . Sesuai dengan hipotesis yang telah ditetapkan jika sig < dari $\alpha$ maka variabel independen berpengaruh terhadap variabel dependen.

Uji regresi linear berganda dan uji t menunjukkan variabel marketing mix-7p berpengaruh positif dan signifikan terhadap keputusan menjadi nasabah PT. Bank BRISyariah KCP Wahid Hasyim Jombang, artinya $\mathrm{H}_{1}$ dalam penelitian ini diterima yang berbunyi, variabel marketing mix-7p berpengaruh positif dan signifikan terhadap keputusan menjadi nasabah PT. Bank BRISyariah KCP Wahid Hasyim Jombang. Jadi, semakin tinggi prinsip-prinsip marketing mix-7p diterapkan maka mengakibatkan semakin tinggi pula keputusan menjadi nasabah yang dihasilkan.

Berdasarkan hasil uji koefisien determinasi dengan nilai $(R)=0,885$, nilai koefisien determinasi atau $\mathrm{R}$ square sebesar 78,3\%, artinya variabel independen mempunyai pengaruh terhadap variabel dependen sebesar 78,3\%. Sementara itu dan 
sisanya $22.7 \%$ dipengaruhi oleh variabel-variabel lain yang tidak diteliti dalam penelitian ini.

Diantara indikator variabel marketing mix-7p yang terdiri dari produk, harga, tempat, promosi, orang, proses, lingkungan fisik yang paling dominan terhadap keputusan menjadi nasabah PT. Bank BRISyariah KCP Wahid Hasyim Jombang adalah indikator tempat dengan nilai beta sebesar 0,267, artinya indikator tempat ini adalah indikator yang paling besar pengaruhnya terhadap keputusan menjadi nasabah PT. Bank BRISyariah KCP Wahid Hasyim Jombang.

Sehubungan tempat adalah indikator yang paling mempengaruhi dari pada indikator lainnya dalam penelitian ini disebabkan karena lokasi kantor sangat strategis karena terletak di jalan utama dan tempat umum seperti pusat perbelanjaan, sehingga mudah dijangkau oleh masyarakat selain itu gedung dan ruangan nasabah PT. Bank BRISyariah KCP Wahid Hasyim Jombang sangat nyaman, sehingga mempengaruhi keputusan menjadi nasabah PT. Bank BRISyariah KCP Wahid Hasyim Jombang. Selain itu nasabah juga setuju bahwa dengan pemilihan lokasi yang tidak terlalu ramai (ke pusat kota), karena dapat memecahkan keramaian, kemacetan lalu lintas dan meminimalisasi tingkat kerawanan yang bagi mereka merupakan faktor penentu kenyamanan dan keamanan.

\section{Pengaruh Religi Secara Parsial Terhadap Keputusan Menjadi Nasabah PT. Bank BRISyariah KCP Wahid Hasyim Jombang}

Dari hasil uji yang telah dilakukan, menunjukkan bahwa variabel religi berpengaruh positif terhadap keputusan menjadi nasabah PT. Bank BRISyariah KCP Wahid Hasyim Jombang. Dari hasil peritungan koefisien regresi religi diperoleh nilai sebesar 0,644 dan nilai constant sebesar -5,792, angka tersebut menunjukkan bahwa religi berpengaruh terhadap keputusan menjadi nasabah PT. Bank BRISyariah KCP Wahid Hasyim Jombang. Artinya religi meningkatkan keputusan menjadi nasabah sebesar $0,644 \%$ dengan kata lain jika religi meningkat sebesar 1\% maka keputusan menjadi nasabah juga akan meningkat sebesar 0,644\%.

Signifikansi pada uji t menunjukkan variabel religi berpengaruh terhadap keputusan menjadi nasabah PT. Bank BRISyariah KCP Wahid Hasyim Jombang, dilihat dari nilai signifikansi religi sebesar 0,001 artinya, nilai sig lebih kecil dari 0,05. Sesuai dengan hipotesis yang telah ditetapkan jika sig < dari $\alpha$ maka variabel independen berpengaruh terhadap variabel dependen.

Uji regresi linear berganda dan uji t menunjukkan variabel religi berpengaruh positif dan signifikan terhadap keputusan menjadi nasabah PT. Bank BRISyariah KCP Wahid Hasyim Jombang, artinya $\mathrm{H}_{1}$ dalam penelitian ini diterima yang berbunyi, variabel religi berpengaruh positif dan signifikan terhadap keputusan menjadi nasabah PT. Bank BRISyariah KCP Wahid Hasyim Jombang. Jadi, semakin tinggi prinsip-prinsip religi di terapkan maka mengakibatkan semakin tinggi pula keputusan menjadi nasabah yang dihasilkan.

Berdasarkan hasil uji koefisien determinasi dengan nilai $(\mathrm{R})=0,885$, nilai koefisien determinasi atau $\mathrm{R}$ square sebesar 78,3\%, artinya variabel independen mempunyai pengaruh terhadap variabel dependen sebesar 78,3\%. Sementara itu dan sisanya $22,7 \%$ dipengaruhi oleh variabel-variabel lain yang tidak diteliti dalam penelitian ini.

Berdasarkan hal tersebut, dapat disimpulkan jika tingkat religi meningkat maka, hal tersebut akan meningkatkan pengambilan keputusan seorang menjadi nasabah 
PT. Bank BRISyariah KCP Wahid Hasyim Jombang. Hal ini membuktikan bahwa penerapan religiusitas telah sesuai dengan harapan nasabah dan faktor religiusitas sangat efekif untuk mendorong umat muslim menjadi nasabah PT. Bank BRISyariah KCP Wahid Hasyim Jombang.

Dari penelitian ini juga dapat diketahui bahwa seseorang akan memilih sesuatu yang memang sesuai dengan keimanan (keyakinan) yang dipercayainya. Perilaku tersebut pada akhirnya akan dapat menentukan keputusannya untuk menjadi nasabah bank syariah dan menggunakan produk atau jasa yang ditawarkan oleh PT. Bank BRISyariah KCP Wahid Hasyim Jombang dalam menunjang aktivitas perekonomiannya. Mengingat selain mayoritas nasabah adalah beragama Islam, sebagian nasabah juga menyatakan bahwa kayakinan atau agama sangat memotivasi mereka dalam menjadi nasabah PT. Bank BRISyariah KCP Wahid Hayim Jombang. Selanjutnya mereka berasumsi bahwa ada dorongan moril yang membuat mereka terdorong menggunakan produk PT. Bank BRISyariah KCP Wahid Hasyim Jombang sebagai sebuah konsekuensi. Kemudian untuk koefisien bebas riba memang dianggap mempengaruhi keputusan menjadi nasabah, dimana hal ini dikarenakan oleh asumsi sebagian masyarakat yang memahami sistem bagi hasil sebagai non-ribawi sedangkan bunga adalah riba.

\section{Pengaruh Marketing mix-7p dan Religi Secara Simultan Terhadap Keputusan Menjadi Nasabah PT. Bank BRISyariah KCP Wahid Hasyim Jombang}

Berdasarkan hasil pengolahan windows for SPSS versi 23.0. Dari hasil uji $\mathrm{F}$ menunjukkan bahwa marketing mix-7p dan religi secara simultan berpengaruh signifikan terhadap keputusan menjadi nasabah PT. Bank BRISyariah KCP Wahid hasyim Jombang. Hal ini ditunjukkan dengan hasil nilai signifikansi pada tabel ANOVA yaitu sebesar 0,000 yang lebih kecil dari 0,05 dengan nilai $\mathrm{F}$ yaitu 174,858 , sesuai dengan hipotesis yang telah ditetapkan jika sig $<\alpha$ maka variabel independen berpengaruh terhadap variabel dependen secara simultan.

Selain itu dari hasil uji regresi berganda diketahui koefisien determinasi atau $\mathrm{R}$ square sebesar 78,3\%, artinya marketing mix-7p dan religi berpengaruh terhadap keputusan menjadi nasabah PT. Bank BRISyariah KCP Wahid Hasyim Jombang sebesar $78,3 \%$ dan sisanya yaitu $22,7 \%$ dipengaruhi oleh variabel-variabel lain yang tidak diteliti dalam penelitian ini.

Berdasarkan data yang telah di uji maka diperoleh nilai korelasi $\mathrm{R}=0,846$ atau 84,6\%, yang berarti hubungan antara produk, harga, promosi, lokasi, karyawan, sarana fisik dan proses layanan terhadap penjualan valas pada PT. Haji LA Tunrung AMC di Makassar memiliki hubungan yang kuat. Kemudian nilai Adjusted $R$ Squaresebesar 0,694 atau sebesar 69,40\% variasi dari penjualan valas dipengaruhi oleh produk, harga, promosi, lokasi, karyawan, sarana fisik dan proses layanan. Sedangkan sisanya sebesar 30,60\% dipengaruhi oleh faktor lain yang tidak dimasukkan dalam model penelitian ini.

\section{KESIMPULAN}

Berdasarkan hasil uji parsial yang telah dilakukan bahwa variabel Marketing mix-7p (produk, harga, tempat, promosi, orang, proses, dan lingkukang fisik) berpengaruh secara parsial terhadap keputusan menjadi nasabah pada PT. Bank BRISyariah KCP Wahid Hasyim Jombang. Dari ketujuh indikator marketing mix-7p 
yang paling dominan berpengaruh terhadap keputusan menjadi nasabah PT. Bank BRISyariah KCP Wahid Hasyim Jombang adalah tempat, karena terletak di jalan utama dan tempat umum seperti pusat perbelanjaan, sehingga mudah dijangkau oleh masyarakat selain itu gedung dan ruangan nasabah PT. Bank BRISyariah KCP Wahid Hasyim Jombang sangat nyaman, sehingga mempengaruhi keputusan menjadi nasabah PT. Bank BRISyariah KCP Wahid Hasyim Jombang.

Berdasarkan hasil uji parsial yang telah dilakukan bahwa variabel religi berpengaruh secara parsial terhadap keputusan menjadi nasabah pada PT. Bank BRISyariah KCP Wahid Hasyim Jombang. Hal tersebut membuktikan bahwa faktor religi sangat efektif untuk mendorong seorang muslim menjadi nasabah bank syariah.

Berdasarkan hasil uji simultan (uji F) yang menunjukkan bahwa marketing mix$7 p$ dan religi berpengaruh secara simultan terhadap keputusan menjadi nasabah. Pengaruh variabel tersebut terhadap keputusan menjadi nasabah PT. Bank BRISyariah KCP Wahid Hasyim jombang atau nilai koefisien determinasi (R2) 78,3\% sedangkan sisahnya sebesar $22 \%$ dipengaruhi oleh variabel lain diluar variabel yang digunakan oleh peneliti. 


\section{REFERENSI}

Abdullah, M. Faisal.(2003). Manajemen Perbankan Teknis analisis Kinerja Keuangan Bank Malang: UMM Press.

Amirin. Tatang M.(2011). Populasi dan Sampel Penelitian 4: Ukuran Sample Rumus Slovin. (Tatangmanguny.wordpress.com).

Kasmir. (2004). Pemasaran Bank. Jakarta. Prenada Media.

Kotler, Keller. (2009). Manajemen Pemasaran Edisi 13 Jilid 1: Erlangga.

Lestari, Alfi Mulikhah. (2015). Pengaruh Religuisitas, Produk Bank, Kepercayaan, Pengetahuan, Dan Pelayanan Terhadap Preferensi Menabung Pada Perbankan Syariah (Studi Kasus Pada Mahasiswa Fakultas Ekonomi Dan Bisnis Universitas Brawijaya Malang). Jurusan Ilmu Ekonomi Fakultas Ekonomi Dan Bisnis.

Muhammad. (2005). Manajemen Bank Syari'ah. Yogyakarta: UPP AMPYKPN. Edisi Revisi.

Murti, John. (2010). Pengantar bisnis (dasar-dasar ekonomi perusahaan), yogyakarta: LIBERTY, cet ke-6.

Republik Indonesia. (2008). Undang-undang Nomor 21 Tahun 2008 (Pasal 1) Tentang Pengertian Perbankan Syariah. Sekertariat Negara Jakarta.

Sudarsono, Heri. (2004). Bank \& Lembaga Keuangan Syariah: Deskripsi dan Ilustrasi, Yogyakarta: Ekonisia.

Sugiyono. (2015). Metode Penelitian Kombinasi (Mixed Methods). Bandung Alfabeta.

Sumitro, Warkum. (2004). Asas-asas Perbankan Islam dan Lembaga-lembaga Terkait (BMUI dan Takaful). Jakarta:PT. Raja Grafindor Persada. 